\title{
LETTER
}

\section{Influence of prior sunlight exposure on ICU mortality - does delirium play a role?}

\author{
Koen Simons*, Mark van den Boogaard, Arjen Slooter and Peter Pickkers \\ See related research by Castro et al., http://ccforum.com/content/16/4/R132
}

With interest we read the article by Castro and colleagues exploring the relationship between sunlight exposure and ICU mortality [1]. Interestingly, less daylight exposure prior to ICU admission was associated with a reduction in ICU mortality. While the authors mention the influence of light on the development of delirium, it is also recognized that delirium is an independent risk factor for death [2-4]. However, the authors did not adjust for delirium.

To determine whether sunlight exposure is still associated with ICU mortality when additional adjustments are made for delirium, we performed a similar retrospective cohort study on 2,623 patients admitted to ICUs of three large hospitals in the Netherlands. The 28-day photoperiod values were retrieved from weather stations in the vicinity of these hospitals from the Royal Dutch Meteorological Institute, including actual sunlight hours per day. The pre-illness photoperiod ranged from 37 to 301 hours. In total, 849 (32.4\%) patients suffered from delirium during their ICU admission and 200 (7.6\%) patients died during their hospital stay. In a multivariate logistic regression analysis adjusting for similar covariates to the Castro group but now also including delirium, the cumulative 28-day photoperiod prior to ICU admission was not associated with in-hospital mortality (odds ratio $=1.001 ; 95 \%$ confidence interval $=0.997$ to 1.005 ).

Naturally, our study population is smaller than that in Castro and colleagues' study and therefore it would be interesting to know whether the reported relationship between sunlight exposure and outcome remains when delirium is added as a covariate. If this relationship does not remain, it could be determined whether delirium is a confounder or a mediator of mortality.

\section{Authors' response}

Ricardo A Castro, Derek C Angus and Matthew R Rosengart

We appreciate the insightful comments and additional adjusted analysis of Simons, van den Boogaard, Slooter and Pickkers. We also acknowledge the known association between delirium and ICU mortality; however, our dataset did not capture this covariate. Our perspective is that delirium may be on the causal pathway between light and outcome, as has been previously suggested. Incorporating this covariate would therefore bias our analysis of the association between photoperiod and mortality towards the null.

Apart from the smaller population size, additional characteristics may underlie the disparate results. The lower mortality $(7.6 \%)$ of Simons and colleagues' cohort, in contrast to ours (10.7\%), may similarly challenge the ability to identify a significant difference. Additional data

*Correspondence: k.simons@jbz.nl

departement of Intensive Care, Jeroen Bosch Ziekenhuis, P.O. Box 90153, 5200 ME's Hertogenbosch, The Netherlands from their analysis, including the point estimates prior to any additional adjustment and the means of risk adjustment, would enable a better comparison. Interestingly, the range of the pre-admission photoperiod (37 to 301 hours) for Simons and colleagues' cohort differs considerably from that in our analysis (259 to 421 hours) with only modest overlap. The biologically meaningful cumulative photoperiod occurs after approximately 4 weeks of exposure. Although details of their methodology are not provided, the relationship between light and ICU mortality may exhibit a threshold below which no further benefit is observed. Nonetheless, we appreciate their attention and certainly share their view that further analyses are needed.

\section{Competing interests}

The authors declare that they have no competing interests.

Published: 16 November 2012

References

1. Castro RA, Angus DC, Hong SY, Lee C, Weissfeld LA, Clermont G, Rosengart MR: Light and the outcome of the critically ill: an observational cohort 
study. Crit Care 2012, 16:R132.

2. Ely EW, Shintani A, Truman B, Speroff T, Gordon SM, Harrell FE, Jr, Inouye SK, Bernard GR, Dittus R: Delirium as a predictor of mortality in mechanically ventilated patients in the intensive care unit. JAMA 2004, 292:168-169.

3. Pisani MA, Kong SY, KasI SV, Murphy TE, Araujo KL, Van Ness PH: Days of delirium are associated with 1-year mortality in an older intensive care unit population. Am J Respir Crit Care Med 2009, 180:1092-1097.

4. van den Boogaard M, Schoonhoven L, van der Hoeven JG, van Achterberg T,
Pickkers P: Incidence and short-term consequences of delirium in critically ill patients: a prospective observational cohort study. Int J Nurs Stud 2012, 49:775-783.

doi:10.1186/cc11497

Cite this article as: Simons $K$, et al: Influence of prior sunlight exposure on ICU mortality - does delirium play a role? Critical Care 2012, 16:462. 